\section{BRITISH SCIENTIFIC INSTRUMENTS IN PARIS}

$\mathrm{E}^{\mathrm{A}}$ ARLY last year an exhibition of French scientific instruments was held in the Science Museum, South Kensington. It aroused so much interest that M. René Varin, of the French Embassy, suggested to the British Council that a similar exhibition of British instruments in Paris would have a like success. Thanks to the co-operation of French scientific men and the willingness of British industry, universities and government research organizations to collaborate, the British Council was able to arrange an exhibition during May 11-17 at the Sorbonne. The rooms made available for this purpose adjoined those in which the French Physical Society was holding its annual exhibition of scientific instruments, and visitors could circulate freely from one exhibition to the other.

The new venture was an undoubted success. The exhibits, all selected for their excellence and topical interest, were 'live' in the sense that they showed the products of the instrument maker in use as research tools. In this way the French visitor not only saw up-to-date equipment both in the development and finished stages, but was also afforded a direct insight into the research work of some of the leading and most productive laboratories of Great Britain. The exhibits were explained by enthusiastic demonstrators familiar with their subjects, and whenever language difficulties arose bi-lingual representatives of the British Council and of French scientific research laboratories were ready to help. A descriptive catalogue in French gave details of the thirty-nine exhibits and of the nature of the work with which they were associated. Explanatory display cards were also provided.

A complete list of exhibits would be out of place here; but it would be true to say that all evoked much interest, while the almost permanent congestion about some marked them out as 'high-lights' from the French point of view. Among these were the micro-manipulators, the Geiger counters and cathoderay tubes, and the electron diffraction and metal evaporating equipments. The cosmic-ray photographs shown by University of Bristol workers and those taken on the Pic du Midi by University of Manchester students and illustrating the disintegration of $V$-particles were outstanding attractions. The demonstration from King's College (London) of the application of the reflexion microscope in biology, the galvanometers used at University College (London) in physiological research, and the vacuum torsion balances of the British Electrical and Allied. Industries Research Association all attracted much attention. Among exhibits from government laboratories, the electronic calculating machine from the National Physical Laboratory, the Radio Research Station's automatic ionosphere recorder (which functioned throughout the run of the exhibition without a hitch), the Atomic Energy Research Establishment's machine for producing quartz fibres, the Telecommunications Research Establishment's millimetric wave spectrometer and the 2,000-ehannel frequency-generator and automatically recording resistance extensometer of the Royal Aircraft Establishment aroused eager and continual interest and discussion.

There was a time when the man of science could keep abreast of the work of his colleagues by private correspondence and through publication. This is no longer possible. Enormously increased scientific activity and growing complexity of experimental methods have so swollen the literature that direct interchange of ideas and experiences is now vital to progress. This is made all the more necessary by the breaking down of the compartmentation within science owing to the rapid expansion of the borderline fields of research between two or even more disciplines. The need is only partially met by international conferences, which touch but lightly on techniques and methods, being more concerned with results and conclusions. But the ways by which results are obtained are no less important, and here the mutual interchange of visits to laboratories is of the greatest possible value. This exhibition of British scientific instruments and research is a step in the right direction in that, to some extent at least, it opened the laboratory of the British experimental scientific worker to inspection by his French colleagues, just as, during their week's stay, British visitors were given facilities to see the laboratories of the leading scientific organizations in France. It is to be hoped, therefore, that this kind of exhibition exchange between the two countries may become a regular event. There is no room for isolationist nationalism in the development of instruments and techniques for scientific research.

The exhibition was opened by Prof. E. N. da C. Andrade, and during the week lectures were given by him, Dr. V. E. Cosslett and Prof. G. I. Finch on recent work carried out in their laboratories. Yet another link between French and British science was forged by the award to Sir Thomas Merton on May 15 of this year's Holweck Prize given jointly by the Société Française de Physique and the Physical Society.

The following French scientific bodies gave valuable assistance in the organization of the exhibition : the Centre National de la Recherche Scientifique, Office National d'Etudes et de Recherches Aeronautiques, Commissariat à l'Énergie Atomique and the Société Française de Physique.

G. I. FINCH

\section{TELEVISION STATION AT BIRMINGHAM}

$\mathrm{A}^{\mathrm{T}}$ T a meeting of the Radio Section of the Institution of Electrical Engineers on May 9, a symposium of three papers was presented on the technical features of the television broadcasting station at Sutton Coldfield, near Birmingham, which was opened for public service on December 17, 1949.

The first paper, presented by P. A. T. Bevan and H. Page, described the design, construction and service performance of the Sutton Coldfield station, which was built by the British Broadcasting Cor. poration as a first step in the extension of its television service to the provinces. By adopting vestigial sideband transmission for the vision programme, in place of the double sideband method installed at Alexandra Palace, London, before the Seeond World War and still in use there, it has been possible to provide five independent channels within the band 41-68 Mc./s. allocated to the television service in Great Britain. At Sutton Coldfield, there are two very-high-frequency transmitters-a $42-\mathrm{kW}$. vision transmitter and a $12-\mathrm{kW}$. sound transmitter, operating on carrier frequencies of $61 \cdot 75$ and $58.25 \mathrm{Mc} . / \mathrm{s}$., 